\title{
Las tres vías \\ Dos manuscritos inéditos del Bto. Alonso de Orozco ${ }^{1}$
}

\author{
INTRODUCCIÓN
}

Tiene Valladolid una deuda contraída hace siglo y medio con el beato Alonso de Orozco desde que, a raíz de la fatídica y desastrosa desamortización y extinción de las Corporaciones Religiosas en España, 1835-1837, el entonces Comisario de misiones en Filipinas, P. Francisco Villacorta, pudo salvar y salvó innumerables manuscritos del famoso convento de San Felipe el Real, tanto relativos al santo de San Felipe, Alonso de Orozco, como de la Orden en general.

Es verdad que el P. Tomás Cámara, al fundar la Revista Agustiniana ${ }^{2}$ en Valladolid en 1881, tenía, entre otros objetivos, publicar todos los manuscritos inéditos de nuestro beato; pero la elevación del fundador y director de la Revista al episcopado por un lado, y la nueva orientación que le dio le imprimió el P. Conrado Muiños por otro, hizo que permaneciera en espera multitud de material inédito tanto del beato Alonso de Orozco como de otros agustinos.

La celebración del IV centenario de la muerte del beato Alonso de Orozco es ocasión propicia para ofrecer a nuestros lectores algunas de esas obras inéditas.

Permítaseme adelantar que el archivo de los agustinos de Valladolid, está constituido primeramente con la correspondencia del provincial de Fili-

1. APAF (=Archivo de la Provincia Agustiniana de Filipinas), leg. 924/1-2 y 92563-4. El título de cada uno de los cuadernos puede verlos detalladamente el curioso lector en el $\mathrm{P}$. Bonifacio Moral, en su "Catálogo bio-bibliográfico agustiniano de escritores españoles y portugueses", en: La Ciudad de Dios 18 (1989) 309-317, 463-467, a quien copian los PP. Antonio Blanco (Biblioteca bibliográfico agustiniana del colegio de Valladolid, Valladolid 1909, pp. 428-438, nota) y Gregorio de Santiago Vela (Ensayo de una biblioteca ibero-americana de la Orden de San Agustín, vol. VI, Madrid 1922, pp. 158-166).

2. Revista Agustiniana 1 (1881) 2. 
pinas con el colegio, los documentos oficiales emanados tanto de la Santa Sede como de la Curia Generalicia, de la Corte de Madrid, Nunciatura, obispados, etc.

Tras la nefasta desamortización, queriendo y/o sin querer, vinieron a parar a este colegio-Seminario, único sobreviviente de la hecatombe claustral, libros y manuscritos de diversa procedencia, singularmente de las provincias agustinianas extinguidas.

Lo que en un principio fuera archivo conventual se transformó en archivo de Provincia, singularmente a fines del siglo XIX, cuando se enviaron a la Península muchos fondos de los conventos de Filipinas, principalmente del convento de San Pablo de Manila. Perdidas aquellas Islas para España, la residencia del Superior Mayor se fijó en Madrid, y en Madrid, por consiguiente, se archivaba toda la documentación correspondiente. Posteriormente ese fondo del archivo de Provincia de Madrid fue incorporado a éste de Valladolid formando una sola unidad, lo que obligó a una nueva catalogación $^{3}$, y dándole el nombre antes citado APAF.

Hecha esta aclaración, volvamos a nuestro tema.

Los fondos sobre el beato Alonso son de dos clases: uno, sus manuscritos originales que están en cuatro mamotretos, todos de su puño y letra, salvo excepciones, y que daría lugar a cuatro gruesos volúmenes; la Obra Pía de la canonización de San Juan de Sahagún y beatificación del venerable Alonso de Orozco es el segundo fondo con más de un centenar de legajos, reveladores del movimiento económico que hubo en torno a la Obra desde 1671 hasta 1830.

El tema a presentar ahora es sobre el fondo primero. Predomina en todos los escritos del Beato el tema de la predicación y la dirección espiritual, preferentemente a nivel personal, pero su doctrina es útil y provechosa para cuantos desean adelantar en la perfección. Están en latín y en castellano, y son, en general tratados breves, a veces meros apuntes o esquemas con miras a un posterior desarrollo.

Esto acontece precisamente en el tema que tratamos: Las tres vías, de las que hay dos tratados, el primero se reduce a 7 páginas, mientras que el segundo llena 29. A través de este último, utilizando el esquema del primero, expone a veces con las mismas palabras la doctrina sobre la vida interior en sus tres etapas de purgativa, iluminativa y unitiva. Su lenguaje es coloquial,

3. La catalogación y fichaje fue paciente y eficazmente realizada por el P. Manuel Merino Pérez, auténtico restaurador del archivo en su nueva planta. Su muerte prematura ocurrida el 28 de agosto de 1987 dejó incompleta la catalogación. Ha sido necesaria una tabla de correspondencias entre la vieja y la nueva, lo que evita problemas a los nuevos investigadores. 
fervoroso, espontáneo, accesible al hombre sencillo e ignorante, y de altura a la vez para el sabio o instruido.

Ha parecido oportuno poner ambos manuscritos para ver mejor la evolución del autor. El título del primero es De las tres vías, el del segundo es De las tres vías para hallar perfección el cristiano.

Hago la transcripción directa de los originales, con la ortografía de hoy, respetando las palabras castizas e identificando las citas bíblicas y referencias más claras de los Santos Padres.

\section{TEXTOS}

I

\section{DE LAS TRES VÍAS}

Exercitabar et scopebam spiritum meum (Ps 76,7)

Lavabo per singulas noctes lectulum meum (Ps 6,7)

Ab Oriente venerunt (Mt 2,1)

Longe a peccatoribus salus (Ps 118,155)

Llámase vía purgativa porque ella sale de la culpa y viene a Jesucristo. Deste dolor se despiertan algunos con las penas merecidas por el pecado; otros más se mueven con ver los bienes que perdieron: la gracia de Dios, la compañía de los ángeles, el gozo perpetuo, etc.; otros, más agradecidos, consideran los beneficios universales de Dios y particulares, su misericordia que no ejecutó luego empeñando su voluntad en esperar, etc.

Para pasar adelante ha de ver dos cosas. Ansí la primera que se ve hábil y ligero para orar y hacer las obras del espíritu que es gran señal que marca el Espíritu Santo, en el qui spiritu Dei aguntur hi filii Dei sunt (Rom 8,14). La segunda que cuando considera sus pecados ya no saca dolor sino hacimiento de gracias y motivo de amor de Dios. Esto es, sería que ya Dios se da por contento de lo pasado que se ha dolido. Misericordia motus super eam dixit illi: nolli flere (Lc 7,13). Et Mariae Magdalenae dixit: mulier quid ploras (Jo 20,13). Félix anima cui Dominus dixit adhuc vivens in hoc exilio: euge, serve bone, intra in gaudium Domini tui (Mat 25,21s).

Talis pergat ad viam illuminativam. 


\section{De vía ILLUMinativa}

Accedite ad eum et illuminamini et facies vestrae non confundentur (Ps 33,6). Dice que seamos alumbrados porque el entendimiento recibe una lumbre manifestadora del que la da que es Dios, habiéndose nuestra ánima con Él como el espejo con el sol que si está con orín no resplandece, y cuanto más puro más resplandor recibe por rayos directos que es inmediatamente de Dios, o por reflejos que es, como dice San Pablo, subiendo de las criaturas a Dios. Invisibilia Dei per ea quae facta sunt (Rom 1,20). Ansí como dando el sol en una pared vuelven sus rayos al espejo, Dios resplandece y alumbra nuestra ánima por las criaturas, mas cuando sin medio alguno Él alumbra, levanta el ánima en una admiración de la grandeza de Dios la cual contempla y no puede comprender porque es infinita. Figura la Reina Esther y Saba. Dominus illuminatio mea (Ps 26,1). Para esto es menester gran pureza, mas para ser alumbrada el ánima por rayos reflejos en las criaturas conoce novedades de Dios y de sus criaturas que no conocía antes, más o menos según es alumbrada, y ansí se admiran de ver una flor y una piedra alabando a Dios al cual más ven en la criatura que a la criatura misma.

Ansí decía David: Quam magnificata sunt opera tua, omnia in sapientia fecisti videbo coelos opera digitorum tuorum lunas et stellas... etc. (Ps 8,4). Meditabor in omnibus operibus tuis et in adinventionibus tuis exercebor (Ps 76,13).

Ansí, de exercitar esta vida, viendo un árbol con hoja, flor y fruta, mirar que el ánima ha de tener palabras buenas y flores de santos deseos y fruta de buenas obras. Ego posui vos ut eatis... (Jo 15,16). Videamus si vinea nostra floruit (Cant. 7,12). De foliis et floribus eius non desinet?

$\mathrm{Y}$ porque todo esto causa el amor santo, diga: Oh amor puro, abrasa mi corazón, inflama mis entrañas. Oh buen Jesús, ¿cuándo te amaré?

Ves un caballero en un caballo que rige con su freno y hace correr con las espuelas, di: ;oh amor dulce, oh freno suave, si te poseyese yo! ¡Oh temor filial, si me hirieses y llagases para vencer mi pereza!

Consideras cosas graciosas, pasa a la gloria; si las feas, mira la fealdad del pecado, del demonio y del infierno.

En las criaturas siempre se referirá al provecho del alma y al amor divinal como a fin principal. En las promesas y amenazas se ha de ver como dijimos de las cosas graciosas y feas... Y si, por su rudeza, no sabe sacar lumbre de las criaturas ni sabe letras haga un manojo de beneficios que más sintiere que le inflaman en amor de Dios generales ansí como creación y redención, 
o de los particulares que ha recibido, y puestos sobre el corazón meditando inflame su corazón considerando cuanto amor debe a quien tanto le amó. Diligam te, Domine, fortitudo mea (Ps 17,2). Hanse de ayudar, como una mano a otra, el entendimiento y el afecto.

En la Pasión considere el gran dolor y la paciencia y humildad de Jesucristo. La causa que son sus pecados, y diga: oh Señor, ¿quién soy yo que tanto me amaste? Quid est homo quod, etc. (Ps 8,5), oh Señor, me amaste más que a ti, pues moriste por mí ¿cuándo te amaré más que a mí? Oh Señor, yo a Vos doy trabajo y Tú a mí descanso y gozo. Oh, si derramase toda mi sangre por ti. Esto muy exercitado por el afecto viene a no usar de la meditación y aun estórbale la que antes le aprovechaba. Y en esto es una la vía iluminativa y unitiva que no difieren sino en más o menos perfecta. Y porque spiritus ubi vult spirat (Jo. 3,8), Dios no se ata a estos modos inflamando el ánima sin arte en otras maneras.

\section{VÍA UNITIVA}

La vía unitiva es un hacerse el ánima un espíritu con Dios por amor. Qui adheret Deo unus spiritus fit in eo (I Cor. 6,17). Mihi adhere Deo bonum est (Ps 72,28). Qui manet in charitate etc. (1Jo 4,16). Para esto tengo tres reglas:

La primera, que ha de continuar este ejercicio no guardando lugar ni tiempo ni devoción porque como el pintor que dibuja haciendo borrones y rasgos feos y después viene a perfeccionarse la imagen la cual no acabaría si la dejase en comenzando el dibujo, ansí en manera que aunque en levantar su afecto sienta fantasías y pensamientos diversos para no producir actos anagógicos porque aun en las dos vías no fue purificada el ánima, persevere en la unitiva aunque sea sin dulzura y no le parezca ser sin provecho, pues en cada acto merece nueva gloria y le estima Dios.

Este ejercicio es útil que él consume las fantasías y da hervor a la tibieza, quita las culpas veniales porque son actos de contrario amor movidos. Verdad es que todo es al principio difícil y después suave.

La segunda regla, que tomes algún santo en tu favor vos sint qui exaudiant, el cual supla por ti lo que faltase, como a la Virgen María y el ángel de la guarda, y ten disposición devota en el cuerpo cuanto pudieres, mirando al cielo que favorece.

Tercera regla, que busques tiempo quieto cada noche demás de lo insinuado para este ejercicio. In die mandavit Dominus missericordiam suam et nocte canticum eius (Ps 41,9). Y también el lugar: intra in cubiculum tuum 
(Mt 6,6) por una hora o dos, y si cansares bájate a la compasión de la pasión de Cristo, y de los prójimos. El dolor de lo primero con la crecida perfección de su amor, y de lo segundo se aumenta porque Cristo padeció con gozo, más la compasión de los pecados ajenos es contra la voluntad de Dios. También estudie en se conformar con la voluntad de Dios en todo, triste o alegre. Todo lo haga a gloria de Dios: orar, ayunar, etc. porque Dios lo quiere. Omnia in laudem Dei facite (1Cor 10,31). Este aviso es grande y va mucho en él.

Amar y servir a Dios con amor y por amor, y mire que más vale un acto perfecto, aunque tibio, que otro imperfecto y con hervor, como poco oro vale más que mucha plata.

Esta vía unitiva procede al revés de las otras ciencias, porque en las otras primero se ha de entender y después obrar, como hace el médico, mas en ésta primera ha de ser la obra y gusto, aunque a ciegas: gustate et videte (Ps 33,9).

No hay letrado que sepa decir qué cosa es acto anagógico sino apoyado por Él. Tres maneras hay de conocer a Dios. La primera natural, invisibilia Dei (Rom 1,20), ansí conocieron a un Dios y gobernador de todo. Otra es alumbrado por la fe, descendens a Patre luminum (Jac 1,17), que nos abre mayores secretos de Dios, que es Trino y se hizo hombre, etc.

Y de las criaturas también hay que es más alto, por unión de amor supereminente. Vobis viam ostendo (1Cor 12,31). Ego diligam eum et manifestabo ei meipsum (Jo 14,21). Esta llama San Dionisio '. Teología mística, y es un conocimiento divinísimo causado por ignorancia que es, dejados los sentidos y ayuntada a los rayos resplandecientes de Dios, unida al que es sobre toda substancia. Llama aquí conocimiento divinísimo, no lo que el entendimiento conoce por obra suya, sino lo que le viene de la obra de la voluntad unida a Dios por amor.

Nota que este conocimiento divinísimo y unión del ánima con Dios sin obra del entendimiento no niego una noticia memorativa que hay en Dios en el cual están amontonadas todas las perfecciones, y por tanto es digno de ser

1. Dionisio Aeropagita, De divinis nomínibus, c. 7. Pseudo Dionisio Aeropagita (entre 480530). Falsamente identificado con el famoso Dionisio, convertido por san Pablo en Atenas (cfr. Act 17,34). Fue discípulo de Proclo (411-485) en Atenas, su influencia fue grande tanto en Oriente como en Occidente, por esa aureola de haber conocido y contactado con la primitiva Iglesia. Su doctrina es abiertamente neoplatónica reflejada en sus obras. La primera y principal es De los nombres divinos, que mereció ser comentada por Santo Tomás de Aquino; La mística teología, o conocimiento de Dios por modo secreto o arcano. Sigue la Jerarquía celeste y eclesiástica, y escribió también una decena de cartas.

Cfr. A. Royo MARín: Los grandes maestros de la vida espiritual, Madrid 1973. Ed. BAC, pp. 139-146). El beato Alonso es uno de sus seguidores. 
amado de todo corazón, y ansí no contradice a nuestro Padre "que nada se puede amar que no se conozca primero" ${ }^{2}$, mayormente que de la unión por amor que darán centellas en la voluntad para que luego salte y se inflame en amor sin detenerse. Esto es de gran destreza. Dirupisti, Domine, vincula mea (Ps 115,16).

¡Oh, qué libertad, qué suavidad y ligereza, Dios mío, amaros yo de todo mi corazón! Oh fuego de amor, inflama mi ánima, oh alegría, oh gozo! ¡Oh todo amable, oh todo desiderable!, ;oh todo bien! Fortis est ut mors dilectio (Cat. 8,6). Infinitum este thesaurum hominibus, magni usi sunt participes facti sunt (Sap. 7,14).

En esta ciencia hay grandes provechos. Ella purga los pecados, quita las malas inclinaciones, vence dulcemente y sin trabajo los vicios huyéndoles el cuerpo como David a la lanza de Saúl (1Sam 18,11), no esperando con escudo, produciendo acto contrario al tal vicio que es mayor trabajo y peligro. Ésta es fuente de las virtudes. Charitas paciens est, benigna est, etc. (1Cor 13,4). Ésta hace que el alma agradezca al que le tiró la lanza por le haber sido causa de tanto bien como es llegarse a su Dios. Ella purifica la fe y la esperanza, ella es de quien está escrito: venerunt mihi omnia bona mihi pariter cum illa (Sap. 7,11). Levantemos, dice San Dionisio ${ }^{3}$, nuestra ánima y será de Dios levantada sin negociarlo nosotros. Introduxit me in cellaria sua Cant. 5,3).

\section{PARA LA VÍA ILUMINATIVA \\ Oración Pater noster}

¡Oh Padre benignísimo, Tú eres el que solo bastas a engendrar hijos por nueva gracia! Entonces seré tu hijo cuando morare en mí tu santo amor. ¡Oh bondad infinita que a todos enriqueces, Padre no de uno sino de todos que a todos te comunicas! Oh si fuese yo digno desta admirable influencia de tu amor. Tú moras en los cielos claros y ligeros y firmes que son los santos, hazme puro y subtil quitando el peso del pecado y dame firmeza para que sea templo tuyo no cesando de ese amor como el cielo no sabe reposar un momento.

Sea tu nombre en mí santificado quitando de mi corazón toda afición terrenal y pesadumbre de culpa. Conozca yo tanto bien y ámeos de todo corazón.

2. S. Agustín: Cfr. De Trinitate 9,3,3;10,11-13.

3. Mistica teología. 
Venga ya, Señor, vuestro reino y señorío y sea vencido Satanás que antes en mí reinaba, tenga trono en mí vuestra ley de amor y no la del mundo, como es ley de tiranía. No reine la soberbia, no la ira ni otro vicio sino sólo Vos.

Hágase vuestra voluntad en la tierra ansí como en el cielo. La tierra de nuestros corazones terrenos arda ya con el amor que arden los ángeles y santos para que sea una nuestra voluntad y la vuestra. Oh quien me diese que vuestra santa voluntad aplacible (sic) y perfecta fuese la mía en unidad de amor.

El pan nuestro de cada día, la gracia que nos da fuerzas; vuestra palabra divina y vuestro santo cuerpo dádnosle hoy para que no muramos de hambre. Oh pan de ángeles, quien te comiese dignamente.

Perdona nuestra deudas, Señor, como nosotros perdonamos a nuestros prójimos, quita mis pecados cuotidianos para que con amor herventísimo (sic) te ame, y pues son tantos los lazos de mis enemigos no tengas por bien que caiga en alguno de ellos; siendo tentado socórreme que soy flaco, confórtame pues puedo pecar.

Líbrame del malo que soy yo mismo, defiéndeme del malino (sic) enemigo que vela y brama para me tragar (I Pet 5,8). Sé mi defensor en toda angustia para que libre y vencedor a ti glorifique y alabe. Amén.

II

DE LAS TRES VÍAS PARA HALLAR LA PERFECCIÓN EL CRISTIANO Amice, commoda mihi tres panes (Lc 11,5)

Como el cuerpo no puede vivir sin su manjar, ansí el ánima no puede sustentarse en la vida espiritual sin el pan de vida que es el amor de Dios. Quien no ama muerto está, dijo San Juan (I Jo. 3,14). Y porque este amor se comunica a las almas en tres maneras, que se dicen vía purgativa, iluminativa y unitiva, diremos que son tres panes que hemos de pedir orando siempre, y halos de dar el amigo verdadero y fiel Cristo, de su mano. Con ellos hemos de nutrir nuestro espíritu que viene de camino peregrinando despúués que salió del pecado.

Y en virtud de este pan de amor caminar como Elías hasta llegar al monte de Oreb (I Reg. 19,6) que es el cielo. Tres panes son que nos han de sustentar estos tres ejercicios; y son aquel orden de "tus canales" que dijo Salomón (Can. 7,6) que después de texido con gran dificultad se puede que- 
brar porque el ánima acostumbrada a este santo ejercicio destas tres vías está tan asida y unida con Dios que nada basta para apartarla de su amor y suavidad.

Tres son los rayos de aquel sol de Justicia, nuestro Dios, los cuales abrasan y queman los montes, según avisa la santa Escritura, comunicando el Señor por estos tres ejercicios sus secretos a las almas que como montes altos contemplan las cosas eternas. Finalmente estos tres ejercicios son los tres caminantes que vio Isaías ir para Dios: unos andan, y son los que en la vía purgativa se ejercitan; otros corren, y son los de la vía iluminativa; finalmente otros vuelan con alas de águila (Is 40,31) por la vía unitiva hasta remontarse de todo lo criado y hacerse unos en espíritu con su Creador y Señor. Tres panes grandes son de mano de gran amigo dados al alma que con insistencia los pide. Veamos cómo se han de comer.

\section{CAPÍTULO I}

\section{QuÉ COSA ES VÍA PURGATIVA}

Meditabar nocte in còrde meo, exercitabar et scopebam spiritum meum. Medito por la noche en-mi corazón, reflexiono e inquiero mi espíritu (Ps 76,7).

Aquí nos da aviso el Rey David diciéndonos cómo se hubo después de ser perdonado cuando se volvió a Dios haciendo penitencia. Medita en la noche; con mi corazón exercitábame y barría mi espíritu. Como sea el pecado la casa de donde partimos y Dios para quien vamos a descansar, menester es gran consideración de nuestra parte conociendo nuestra gran soberbia en ofender a tan gran Señor y Padre nuestro; también hemos de entender la gran bondad del que nos sufrió y esperó no dando luego con nosotros en el infierno como lo hizo con Satanás y con Datán y Abirón, y con los de Sodoma (Núm 16,24; Ps 105,17; Gen 19,24).

Hemos de advertir las grandes pérdidas que por el pecado nos vinieron: perdimos la gracia y el título de hijos de Dios y la herencia del cielo, obligándonos al infierno, e hicímonos indignos de la tierra que pisamos y del agua que bebemos. De entender la gran majestad de Dios que es ofendido y nuestra gran bajeza y maldad sácase un dolor grande con el ánima pesándonos de haber pecado, y un propósito muy firme de no volver a tan mal estado. Aquí comienzan las fuentes de lágrimas como en San Pedro (Mt 26,75; Lc 22,62; Mc 14,72) y la Magdalena (Lc 7,37), y aquí es lavado nuestro corazón y espíritu como Naamán en el río Jordán (II Reg 5,14) quedó limpio de su lepra. Y 
porque, dado que lo principal venga de Dios que da su gracia, nuestro líbero arbitrio entiende en esta obrả santa, dice ahora este gran penitente David: meditaba de noche con mi corazón y barría mi conciencia (Ps 76,7) confesando mis pecados y doliéndome de ellos delante de mi Dios y a los pies de mi confesor.

\section{CAPÍTULO 3 (sic)}

SE DICEN LOS EJERCICIOS QUE HAY EN ESTA VÍA PURGATIVA

Lavabo per singulas noctes lectum meum: Todas las noches inundo mi lecho y con mis lágrimas riego mi estrado (Ps 6,7).

Esto es el principio por donde los santos purifican su corazón gimiendo su vida pasada y llorando abundantemente con lágrimas exteriores e interiores. De la gloriosa Magdalena dice San Lucas que comenzó a regar los pies de Cristo con lágrimas y los limpió con los cabellos (L. 7,38). Y ansí se le dijo al fin de su llanto: ya tus pecados te son perdonados, vete en paz (Lc 7,50). Había lavado el estado de su alma y purificado su conciencia con gran dolor y lágrimas, por eso el mismo día de su conversión se le dieron tales nuevas y tan grande consuelo. Ya plugiese a Dios que después de un año, y aun de diez años lo mereciésemos nosotros oír ansí de la boca de nuestro Salvador.

Mas al fin cumple perseverar y no cansar en tan gran demanda. No cesen tus ojos, decía Jeremías, oh hija de Sión, sacar tus lágrimas en abundancia y llorar tus culpas delante de Dios. (Thren 2,18; Jer 14,17).

Aunque es verdad que el ejercicio ordinario para este dolor que en esta vía se pretende es la consideración de los pecados continuos, mayormente en la noche, en el recogimiento que tomamos, a lo menos en universal mirando nuestra mala vida pasada y diciendo con David: Habed, Señor, misericordia de mí según la gran multitud de vuestras misericordias (Ps 50,3). También se despierta el alma por otros respectos a dolor de sus culpas, que son el infierno, el juicio y la muerte. También hay condiciones más nobles y más inclinadas a la gran virtud del amor de Dios, y tienen por motivo, no estas cosas que he dicho que engendran temor, sino considerar el beneficio de la creación, cómo nos hizo Dios tan nobles criaturas a su imagen y similitud, cómo nos conserva en el ser y vida que nos dio poniendo todo lo criado debajo de nuestro servicio. Mira el beneficio de la Redención tan excelentemente obrado a tanta costa de Jesucristo que nos dio su sangre y su vida; finalmen- 
te contemplar la promesa que nos ha dado de glorificarnos y por esta vía viéndose tan obligados a servir tantas mercedes a Dios, gimen y lloran su ingratitud y maldades diciendo: Oh Padre, cuán mal hijo he sido. Oh Señor, qué traiciones he cometido contra ti. Oh Bienhechor, cuán ingrato soy a tantas mercedes de tu mano recibidas.

También purifica nuestro Señor y lava nuestra alma cuando se ejercita en esta vía con una sequedad grande y angustiosísima que es no pequeño martirio. Otras veces por enfermedades corporales, que son de gran fruto pues nos dan el mayor enemigo vencido, que es la carne; otras veces por un descontento grande de esta vida. Finalmente tiene Dios muchos medios para purgar el ánima que ofendió a su Majestad. Háse de tener una regla y es que la manera que Dios enviare se tome de voluntad que aquella más cumple: y de las que nosotros tomáremos aquella es mejor que más nos mueve al dolor de los pecados, y aquella se siga aunque cada una es buena de las que aquí van señaladas.

\section{CAPÍTULO 4 \\ DEL USO DE LOS SACRAMENTOS PARA PURIFICAR EL ALMA}

Surge et manduca, grandis tibi restat via: Levántate y come, porque te queda todavía mucho camino (I Reg 19,7).

Todo lo que está dicho favorece para limpiar el alma de la escoria de la culpa que es el fin que en esta vía purgativa se pretende, mas a todo ayuda el uso de los sacramentos con aprecio cuidadoso para irlos a recibir. Tenga el cristiano dolor de sus culpas, vaya cada semana a los confesores y reciba la absolución santamente de ellos, porque allí recibe nueva gracia y favor para su alma, y también coma aquel pan celestial figurado en la torta de aquel pan subcinericio que el ángel dio a Elías porque no desmayase en el desierto y largo camino. Éstas son las fuentes del Salvador a donde dice Isaías que hemos de ir a sacar agua con grande alegría (Is 12,3), porque nos las dejó nuestro Señor y mandó que usásemos dellas para nuestra consolación y nuestro alimpiamiento: tesoros son de grande valor que nos allegó nuestro gran Padre para hacer ricas nuestras almas, y mesa que pone esfuerzo a nuestros desmayos. Él los instituyó, levantémonos sacudiendo toda negligencia, comamos este pan celestial, el cual conforta el corazón del hombre y le hace uno en amor consigo Cristo. Aṇsí lo prometió Él a sus convidados que 
dignamente le recibieren, y aun quedarse en el que me comiere y se quedará en mí (Jo 6,55).

Recapitulando estos ejercicios, digo que el cristiano para purificar su alma considere sus pecados en general y gran dolor por haberlos cometido; lo segundo mire el juicio de Dios, el infierno y la muerte; lo tercero piense los beneficios de la creación y conservación, redención y glorificación que Dios le ha prometido, sacando dolor por haber sido tan ingrato a tan gran Dios y Señor; lo cuarto dispóngase cada semana para confesarse y comulgar recibiendo aquel pan celestial en cuya virtud andará el camino largo y peligroso de la vida hasta llegar al monte de la gloria celestial.

\section{CAPÍTULO 5}

\section{DE LAS SEÑALES PARA PASAR A LA VÍA ILUMINATIVA}

Amice, ascende superius: amigo, subid adelante (Lc 14,10).

No es bien que el ánima con una humildad no discreta y demasiado temor se detenga en la puerta o entrada de la casa no queriendo pasar adelante. Esta vía purgativa es entrada para las otras dos que son la iluminativa y unitiva, tanto mejores cuanto más llegan (sic) al fin deseado que es Dios. No aciertan los que como niños siempre se están en la edad primera, siempre aprendiendo y jamás llegando a ser sabios como dice el Apóstol (2 Tim 3,7). La naturaleza tiene sus edades: la niñez, mocedad y edad perfecta, ansí en el camino del espíritu hay principiantes, aprovechantes y avanzados en perfección. Cumple, pues, mirar estos avisos para que el alma sea sabia en entender las señales que Dios le da para pasar a la vía iluminativa.

La primera es si halla en sí una prontitud y ligereza para las cosas de Dios, quiero decir, una voluntad libre, no siéndole grave el yugo del Señor. Y ansí se halló David cuando dijo: Hame dado el Señor pies de ciervo y púsome sobre cosas altas (Ps 17,34). Esta prontitud es don de Dios y ha de venir de su mano que no se puede merecer de nuestra parte.

Llevadme tras vos, decía la esposa, y correremos al olor de vuestros ungüentos, Señor (Cant 1,3). Luego hase de pedir por la oración y entender que nada tenemos que no sea recibido de la mano de Dios, como nos amonesta el Apóstol (I Cor 4,7). La segunda señal es cuando el ánima ya no siente este dolor dado que haga los ejercicios que suele, antes oye dentro de sí unas palabras de gran confianza que dan a su entender lo que a la Magdalena vete en paz (Luc 7,50), y pasa a cosas más altas que ya tus culpas son per- 
donadas. Ansí creo yo que sintió esta señal el rey David cuando dijo: muy alegre estoy de las nuevas que me han dicho: que hemos de ir a la casa del Señor (Ps 121,1).

Hay otra señal y es cuando el alma exercitada en la penitencia y exercicios que hemos dicho se ve inclinada más a amor que a temor; de aquí nace que ya pensando en el infierno no teme sino alaba al gran poder de Dios y su justicia que allí se exercita considerando la muerte no a miedo, sino, dice con San Pablo, deseo ser desatado y gozar con Cristo (Fil 1,23).

El alma que ya siente que el temor se ha vuelto en amor, y de lo que temía antes ya se alegra con mucha humildad, se levante a mayores ejercicios pasando en breve por la vía purgativa siempre y reposando en las otras dos vías que son la iluminativa y unitiva, Ya le dice Dios: "amiga, esposa, sube más adelante, volved en hacimiento de gracias y en deseos de amor lo que antes volvíades en dolor y temor".

\section{CAPÍTULO 6}

\section{DE LA VÍA ILUMINATIVA}

Emitte lucem tuam et veritatem tuam:-Señor: Enviadme vuestra luz, vuestra verdad (Ps 42,3). Oración esta que hacía el santo profeta David pidiendo a Dios que le guiase en el camino claro y ajeno de tiniebla y engaño que es andar en su servicio y amor. Llámala luz de Dios porque la luz natural es corta para llegar a este ejercicio espiritual tan delicado.

La vía purgativa fue un salir de la posada haciendo penitencia del pecado que ya dejó confesándole y gimiendo por haber ofendido a Dios. Esta vía es como el camino que se ha de andar con la luz del cielo que nos lleva al fin deseado que es la vía unitiva a donde nos hacemos unos con Dios.

Llámase iluminativa porque el entendimiento alumbrado de la gracia ya que se purificó el corazón por la penitencia ve cosas admirables de Dios que ni sabe decir ni declarar cómo las puede sentir.

La necesidad de esta lumbre celestial es grande porque, como dice nuestro Padre, ninguna cosa puede ser amada si no es conocida ${ }^{4}$. Y porque como vemos poco a Dios, le amamos poco, por tanto hemos de pedir con humildad esta luz y decir: Dios mío, enviad vuestra luz y vuestra verdad. Vuestra claridad para que os conozca, y vuestra verdad para que me saque de engaño y os ame no amando la vanidad. Y como ahora vemos que el sol en el espejo más claro y puro más resplandece, ansí la luz que es Dios en el alma purificada

4. Cf. nota 2 . 
resplandece más y le enseña más secretos. Aquel sol que resplandecía en los escudos de oro y reverberó en los montes (I Ma 6,39) esto significaba: que Cristo, sol de justicia, cuando halla corazones de oro puro y armados y lustrosos en gracia reverbera y de allí tornan los rayos alumbrando toda la tierra. Esta luz es la que alumbró a san Pablo camino de Damasco (Act 9,3) y le enseñó la verdad. Es la que se dio a los pastores y los guió a Belén donde adoraron al niño Jesús (Lc 2,9). Es la estrella que sacó a los Magos de su tierra y los encaminó hasta el diversorio donde está el Rey del cielo (Mt 2,9).

En dos maneras alumbra el sol: una es por rayos reflexos dando con su luz primero en otra cosa, y de otra manera por rayos directos, y es cuando vos ponéis los ojos en él. Ansí nuestra ánima es alumbrada de Dios, o por medio de las criaturas de las cuales el entendimiento toma conocimiento de Dios, y esto es rodeo y es oficio de esta vía iluminativa como luego diremos; también alumbra nuestra ánima sin medio alguno levantándola y uniéndola consigo por amor, y esto pertenece a la vía unitiva. Y esta es la más excelente vía. Baste, pues, entender que cuanto más nuestra alma fuere purificada y no tuviere orín de afición alguna ni voluntad propia tanto más como espejo claro será alumbrada de la gracia y cuanto menos fuere pura menos participará de esta luz divinal, y verá menos secretos de Dios en las criaturas y en sí misma.

\section{CAPÍTULO 7}

\section{DEL EJERCICIO DE LA VÍA UNITIVA}

Circunfulxit eos lux de coelo: rodeó a los pastores una luz de cielo (Lc 2,9).

Como por vía de liberalidad y no por deuda este don de luz dalo el Señor a quienes quiere, y muchas veces reciben más della los simples y buenos que los muy letrados y presuntuosos; y es porque los primeros empéñanse en amar y no en entender, los letrados al revés: en especular y entender sentencias más que en obrar con voluntad amando a Dios. De aquí es que a estos pastores se les hiciese este favor y no a los letrados y doctos de la Ley; no porque las letras sean malas ni estorben el amor de Dios antes dan fuerza al siervo, porque ellos usaban mal de ellas.

El que ansí es visitado y versado de esta luz hase de ejercitar desta manera caminando con pasos de amor por las criaturas porque esta es obra del alma. 
Mire en las criaturas el poder y saber y bondad del Criador y sacará por lo visible la majestad y poder del Criador que es Dios, como nos enseña san Pablo (Rom. 1,20). En manera que viendo un árbol con sus hojas, flores y fruto ha de ver luego el ánima y entender en Dios una hermosura infinita y eterna de quien participan las flores, cielos y campos. $\mathrm{Y}$ alabarle y darle gracias por la gran riqueza que usó con sus criaturas. Lo mismo mirando al cielo o viendo oro o plata o cualquiera criatura. En esta vía iluminativa se ejercitaba el rey David cuando dijo: Oh cuan engrandecidas son vuestras obras, Señor, todo lo obrasteis con sabiduría (Ps 91,6).

También pertenece a la vía iluminativa sacar de todas las cosas doctrina para el alma: viendo un árbol verde y con fruto aplicarlo al amor de Dios que es raíz, planta por la cual el alma da hojas de santas palabras, flores de buenos deseos y obras de gran valor.

Aquí ha de orar el alma deseando y pidiendo este amor santo de donde tantas grandezas manan.

¡Oh mi buen Jesús, quién te amase de todo corazón! ¡Oh hermosura eterna, cuándo darás lustre a mi ánima! ¡Oh cuán tarde te conocí y te amé! ${ }^{5}$.

De las cosas, si son feas y estériles, se ha de sacar cuán feo es el infierno, cuán estéril donde no hay amor de Dios, y decir: ¡Oh mi Dios, no os apartéis de mí, no me dejéis caer! Destas mediaciones salen centellas de amor de las cuales dice el profeta que se acendra fuego en su alma (Ps 38,4). Y mira que siempre andes con aquel acto de la voluntad. ¡Oh si os poseyese, mi Dios, si os amase con toda mi alma! porque es el fin de esta vía iluminativa.

\section{CAPÍTULO 8}

\section{CÓMO EN LA ESCRITURA SE HA DE EJERCITAR EL ALMA}

Omnia quae scripta sunt ad nostram doctrinam scripta sunt ut per consolationem scripturarum spem habeamus: todo lo que está escrito para nuestro enseñamiento se escribió para que por la consolación de las Escrituras tengamos esperanza (Rom 15,4).

Como instructiva es y doctrina de San Pablo el cual nos enseña a leer las Escrituras para dos cosas: la primera saber, la segunda para consolarnos y esperar lo que se nos promete de parte de Dios.

Ansí como de las criaturas por la luz de la gracia ha de sacar el ánima doctrina y actos de amor anagógicos según ya declaramos, de la Escritura sagrada, quien la lee, ha de considerar el poder, saber y bondad de Dios que

5. Cfr. Confesiones $10,27,38$. 
la mandó escribir. En la cual o hay promesas de premio para quien ama a Dios y le sirve, o amenazas de castigo para quien le ofende, o hay mandamientos y declaración que Dios da como quiere ser servido, y de todo ha de levantarse el alma y moverse a amar a Dios. Si me promete premio por le amar, es gran bondad suya, pues bastaba por su servicio darme su amor; y quiere mi servicio por enriquecerme a mí y no por sí. Si me amenaza, amor es grande que me enseña, pues para que le ame me pone la espada de su justicia a los pechos. Si me enseña y manda que le sirva, nace de gran amor de Padre porque no quiere que yerre en le servir sino que acierte. En manera que toda la Escritura santa y cualquiera palabra della me pregona amor, y me declara la caridad inmensa de mi Dios.

Pongamos ejemplo en la lectura del Pater noster. Cuando lo leemos digamos así: ¡Oh Padre nuestro, que por gracia nos hiciste tus hijos y nos heredaste en el cielo, danos tu amor título de hijos legítimos y herederos. Padre, que no quisiste un Hijo sino muchos porque más te comunicases y te gozásemos todos.

Estás en los cielos que son tus santos, firmes y perseverantes como el cielo, hermosos con muchas estrellas de virtudes, y en continuo movimiento de amor ocupados, dame, Dios mío, que sea yo cielo y trono tuyo. Oh mi honra de amor que ensanchas el ánima que sea casa de Dios.

Santificado sea tu nombre en mí que deseo conocerte sin mezcla de afición de la tierra; esto no puede ser sin la presencia de tu amor, el cual obra en mí que sólo Tú seas loado y amado. Oh Padre celestial, venga ya tu reino, reine en mí tu gracia, desterrado el tirano que es Satanás, el mundo y el amor propio. Oh ¿cuándo mandará mis sentidos y potencias del alma tu santo amor ardentísimo? Danos ese reino de gloria para que fuimos criados, oh Rey del cielo, acábase ya nuestra peregrinación.

Hágase, Señor, vuestra voluntad en la tierra que son los pecadores ansí como se hace en el cielo claro y firme y ligero que son los justos. Oh fuerza de amor que bastas a hacer de dos voluntades una ¿cuándo seré del todo unido en espíritu con mi Dios para que mi voluntad sea la suya?

Danos el pan nuestro que es de cada día. Danos hoy, Señor, no sólo el pan corporal para la vida del cuerpo corruptible sino aun provéenos del pan sabroso del amor, el cual se aumente y crezca cada día siendo nuestra alma con actos de vivo amor levantada a ti porque no desmaye y caiga en pecado.

Perdónanos, Padre, nuestras deudas, como nosotros perdonamos a nuestros deudores. Oh deudas mías, pecados pasados y presentes con qué podré pagaros sino con aquella moneda preciosa de amor que la Magdalena pagó. Oh Dios mío, que este amor de tu mano me ha de venir pues excede mis 
fuerzas. El me librará de mis culpas cuotidianas y de las antiguas, $¡ \mathrm{Oh}$, gran tesoro el del amor si la tuviese yo!

No nos dejes caer en la tentación, Padre santo. Grande es nuestra flaque$\mathrm{za}$, grande el rigor de nuestros contrarios, mas la virtud de tu amor nos guardará si nos atas contigo, Señor. Oh amor, más fuerte que la muerte ${ }^{6}$, pues juntas lo flaco con lo fuerte, llégame a mi Dios y no caeré en la tentación.

Líbranos del mal. Líbranos del mal de la culpa porque no carezcamos de ti, Señor. Líbranos del mal de la pena, no por el dolor que sentimos, sino porque se nos dilata tu vista. Oh Señor, líbranos del demonio que nos persigue, y del mundo y de nuestras malas inclinaciones. Oh amor santo, que tú lo puedes todo remediar. Tú consumes la culpa y deshaces la pena. Tú haces animosas las almas y ganas la victoria. $\mathrm{Oh}$, si poseyese yo siempre para que jamás fuese vencido de mis enemigos. Padre poderoso, dame tu divinal amor.

De esta manera se ha de ejercitar el que lee la Escritura santa.

\section{CAPÍTULO 9}

CÓMO POR LA CONSIDERACION DE LOS BENEFICIOS SE HA DE EJERCITAR EN LA VÍA ILUMINATIVA

Quid retribuam Domino pro omnibus quae retribuit mihi: ¿Qué pagaré al Señor por tantos beneficios como me ha hecho? (Ps 115,12).

El profeta David, congojoso y solícito en considerar los beneficios de Dios, hablaba consigo mismo estas palabras.

Ya en el tratado que se dice Gratitud Cristiana ${ }^{7}$ hablamos desta materia, aquí la tornemos brevemente. Si alguno se sintiese inhábil para sacar meditaciones inflamativas de las Escrituras como ya dijimos, o si, por falta de saber, no acertase a se ejercitar en la Escritura, tome esta manera que podría ser que en ella aprovechase más que en las dos ya declaradas.

Haga un montón de los beneficios que recibió. El primer beneficio es la creación, el cual considerando el rey David, dijo: tus manos, Señor, me hicieron y me plasmaron, dadme entendimiento para saber vuestros mandamientos" (Ps 118,73).

6. Cfr. Cant. 8,6.

7. Gratitud cristiana o como ser agradecidos con Dios. En tres capítulos expone los motivos para ser agradecidos con Dios, Creador, Redentor y Glorificador. Es extracto, dice el mismo beato, de la meditación para el ejercicio del miércoles apuntado en el Memorial de amor santo, mirando a Jesucristo ansí como emprestador de quien tiene emprestados todos los bienes (cap. XII). Esta obrita suele ir a continuación del citado Memorial. Cfr. Obras del Ven. siervo de Dios Fr. Alonso de Orozco..., $2^{\mathrm{a}}$ ed. Madrid 1726, tomo II, pp. 338-344. 
A este profundo hemos de acudir cuando buscamos nuestra anihilación, ponernos en aquella tiniebla de la nada que éramos por nosotros mismos en eternidad; y la razón dice que lo que es nada ni puede merecer ni darse el ser a sí mismo, luego debo a la bondad de mi Dios el ser que tengo el cual me le dio por pura gracia y amor suyo. Aquellas poderosas manos suyas echaron mano de mi nada y hiciéronme algo, y no cualquiera cosa, no piedra, ni árbol, ni ave, como dice nuestro Padre, sino hombre, la más excelente criatura de este mundo visible ${ }^{8}$. Hiciéronme carne y cuero, estas manos labráronme como de masa de lodo, dice Job (Job 10,9), todo a la medida me artifició mi criador. Diéronme vida dándome un alma hecha de la nada para que a nada me incline sino que solamente ame a su criador. $Y$ tal que entienda, se acuerde lo pasado y tenga libertad para querer y no querer.

Los filósofos dieron un mismo nombre a Dios y al alma llamándola mente, porque se parecen mucho Dios y ella. Pues si el fin para que nos crió miramos, no poco inflama nuestro amor, fue para gozar del criador que nos hizo y para vestir de su librea de inmortalidad y de gloria y reinar sin fin con Él. De donde le nace tan gran hambre que todo lo criado le parezca grano de mostaza para tener hartura. Aquí tiene el alma materia bien abundante y mesa cumplida para levantar su afecto y saliendo de sí misma dar voces: $\mathrm{Oh}$ mi hacedor, oh Padre, que siendo por mí nada, me sacaste de aquella tiniebla y me diste ser y tal ser. Alábote, Dios mío, glorifícote y todo lo criado te alabe. Oh amor infinito, enciende mi corazón en tu amor para que en ti me ocupe solo.

Si debo amor a mis padres, instrumentos de lo menor que yo tengo que es mi cuerpo, a ti, mi criador, que me hiciste y eres el artífice principal del cuerpo, y a solas me diste esta alma que te debo, ¿con qué pagaré tan grande deuda?

El beneficio segundo que es la conservación del ser que nos dio este magnífico Señor no es de menos estima que el primero pues cada momento que nos conserva nos está dando el ser como de nuevo, pues si nos dejare de su mano luego nos volveríamos al no ser de donde salimos. Esto consideraba el rey David cuando dijo: Señor, me formaste y pusiste sobre mi tu mano, susténtasme teniéndome de tu mano poderosa (Ps 138,15).

Los rayos del sol anihílanse en anocheciendo porque se ausentó el sol, ansí todo lo criado se desharía si Dios alzase su mano del mundo. Insinuó este beneficio a nosotros, alma cristiana, cuando por Oseas nos dijo: ansí como amé a Efraín, lo traía en mis brazos y ellos no lo entendieron (Os 11,3). Este es todo nuestro mal, hermanos, no considerar en cuyos brazos anda-

8. Cf. Ciudad de Dios 19,13,2. 
mos, no mirar a nuestro gran Padre que nos crió y nos conserva en los brazos de su providencia.

Muchas madres buscan amas que les crien sus hijos no pudiendo sufrir tanto trabajo. Oh mi Dios, tú eres más que madre mía, que tú me criaste y me traes en tus brazos siempre, ¿cómo no te amo de todo mi corazón?, ¿cómo no miro al que siempre me mira y me regala y me sustenta?

En este beneficio hay otros muchos escondidos que no tienen número. Todas las criaturas trae Dios ocupadas en mi sustentación. Los cielos por mí se menean, las nubes por mí llueven, la tierra y elementos por éste hacen sus operaciones, y aun todos los ángeles y espíritus celestiales, dice san Pablo, que son oficiales desta casa de Dios, y entienden en la salud de los hombres (Heb 1,14). Oh, qué razón tenía David de admirarse y decir: Señor, quién es el hombre que ansí os acordáis de él y el hijo del hombre que le visitáis? Hicístele un poco menor a los ángeles, coronástesle (sic) de gloria y honra y dístele señorios sobre todas las obras de vuestras manos. Oh cuán maravilloso es, Señor, vuestro nombre sobre la tierra (Ps 8,5-10).

De manera que todos los beneficios que Dios hizo a todo lo que crió son míos, pues todas las cosas me sirven a mí y se emplean en mí. ¿Qué será, alma, si entras dentro de ti misma a considerar los particulares bienes que te ha hecho Dios y de los males que te ha librado que son beneficios privativos más difíciles de conocer que los positivos? Baste para inflamar tu afecto que todos los males que ves en otros son beneficios tuyos, pues no te los dio Dios siendo tú pecador como los otros y hombre mortal como los otros.

El beneficio de la Redención es tan altísimo y excede tanto a los pasados que no hay lengua que lo pueda decir. Determinó Dios para más ganar nuestro amor y del todo conquistar nuestro corazón hacerse hombre por los hombres, comunicarles sus riquezas tomando las miserias de ellos. Oh cuantos bẻneficios encierra en sí este beneficio. Abre los ojos, alma, y comprende, si puedes, qué merced tan grande es que tu Criador no enviase un ángel como dice Él por Isaías (Os 63,9), sino que Él personalmente ha venido, peregrinando en la tierra tantos años, padeciendo hambre, sufriendo injurias de sus enemigos y otros trabajos sin número.

Finalmente qué corazón hay tan de piedra que, viendo al que es libertad atado, y al que es alegría del cielo agonizando y triste, a quien es inocente azotado y coronado de espinas y enclavado en un madero, no dé voces y diga: mi amado, santo esposo, Cristo, a mí y yo a Él (Cant 2,16). Él no quiere ni busca sino a mí, no buscaré ni quiero otra cosa sino a Él. Él me da su vida, yo le daré la mía. Oh cama estrecha del más sabio que Salomón, oh trono penoso que por ti se ganan las sillas de los predestinados. Oh gran Jacob animoso que con esas vestiduras ajenas me ganáis a mí la bendición del Padre 
celestial (Gen 27,15). ¿Qué te daré, Señor, por tan gran merced y tan a tu costa, sino amarte y jamás de ti olvidarme? Oh si nunca quitase de ti mis ojos, mis deseos y mi amor. Oh mi Dios, no sea yo el hijo abortivo, que pare con dolor la madre y no goza del favor de la vida, no sea yo ingrato a tan magníficas mercedes.

Finalmente, si quieres levantar tu afecto y que suban tus deseos como llamas de fuego de amor considera el último beneficio de la glorificación para la cual resucitó nuestro Salvador glorioso y triunfó de la muerte. Este tesoro es el gran paradero y mar que encierra todos los beneficios pasados. Si te crió de la nada y te hizo a su imagen y similitud fue para este fin que es glorificarte. Si se hizo hombre y padeció muerte tan espantosa fue para merecer esta joya de tu gloria. Si te llamó al bautismo y te dio mejores joyas que a Rebeca, esposa de Isaac, le fueron dadas (Gen 24,22), todas fueron medios para este fin.

Pues de manera, hermano, entre tantos infieles y bárbaros que se condenan, que hayas tú sido nacido de padres cristianos y baptizado ¡qué beneficio tan grande es éste! Pues si pasas adelante: haberte perdonado tus pecados, haberte dado gracia para que no tornes a ellos, haberte llamado por tantos medios, predicadores, inspiraciones y llamamientos tan diversos, cada cosa destas es un gran beneficio de Dios, los cuales como ríos portan en el beneficio grande de la glorificación.

Levántense, pues, ya el alma y reconocida de tanta leña de beneficios gima y dé voces a Dios y como el Ave Fénix encienda fuego destas meditaciones y diga con San Pablo: gracias a Dios que nos dio victoria por Jesucristo nuestro Señor (I Cor 15,57). Llame a las criaturas todas y diga con David: engrandeced al Señor conmigo y ensalcémosle en eso mismo (Ps 33,4).

El demonio se admiró del cerco que Dios tenía puesto a todas las cosas de Job (Job 1,10), y ansí guarda Él y favorece siempre a sus amigos que le sirven haciéndoles grandes beneficios que ellos muchas veces no entienden ni pueden entender. Oh ánima, no te olvides de las mercedes que tu Dios te hace, decía David (Ps 102,2), sé grata a quien tanto te ama y dale la paga de amor que Él pide y busca. Y pues ves a tu Señor todo regalado de amor en la cruz por ti dirá con la esposa mi ánima se ha derretido y regalado en oyendo hablar a mi amado, Cristo (Cant 5,6).

En esta consideración de los beneficios recibidos nadie hay ignorante o rudo, pues el buey, dice el Señor, que conoció su poseedor que le da de comer y el asno tuvo conocimiento del pesebre donde recibe el mantenimiento (Is 1,30). Otros animales más sagaces y vivos hay como el elefante y el perro, y no quiso el Señor sino tomar por ejemplo los más rudos porque se vea la gran culpa que tiene el hombre ingrato. No tome el cristiano como por 
tarea la consideración destos beneficios todos, sino, como da de comer al cuerpo por tasa y no con exceso, dé mantenimiento a su alma teniendo aviso que la meditación y el afecto anden como dos manos que siempre la una ayude a la otra.

Tiene nuestro Dios otras diversas maneras cómo alumbrar el ánima e inflamarla en su amor, por tanto dijo san Juan que la unción del Espíritu Santo nos enseña todas las cosas (I Jo 2,27). Él alumbra y da dulzura como quiere, donde quiere y cuando quiere. Dispónganse nuestra alma y que Él no nos faltará jamás enseñándonos grandes cosas de sí.

\section{CAPÍTULO 10}

De LA VÍA UNITIVA

Qui adheret Deo unus spiritus est cum eo. El que se llega a Dios hácese un espíritu con Él (I Cor 76,17).

Gran esfuerzo nos da aquí San Pablo para nos exercitar en la vía última que llamamos unitiva, pues por ella nos hacemos divinales siendo ya unos en el espíritu con nuestro criador. No basta allegarnos a Dios por conocimiento solo contemplando cosas grandes de su majestad, que esto los filósofos con la lumbre natural lo hicieron, según el mismo Apóstol lo afirma (Rom 1,20), menester es con otra lumbre más alta que es la fe entender cosas altas de nuestro Dios las cuales nuestro entendimiento no basta para penetrar por sí solo; a esta luz conviene, según ya en la vía iluminativa declaramos, contemplar en las criaturas al criador dellas, y ver más a Él en ellas que a las mismas criaturas de manera que cada criatura nos pone como trono ataviado donde está sentado el criador poderoso, sabio y bondad infinita, sea la criatura cual se ofreciere a los sentidos o al entendimiento. Oh dichosa el alma que ya ha llegado a tan alta sabiduría y a tan grande perfección que en todo ve a Dios, gusta su dulzura admirable y siente la hermosura del criador.

Mas en esta vía unitiva que es por acto hervoroso de amor muy otra cosa pasa; el entendimiento está como ciego, los sentidos quedan dormidos, todo está en silencio, salvo la voluntad que gusta y se regala amando a su Dios. Gustad y ved cuán suave es el Señor, decía el Profeta (Ps 33,9), gustad amando porque entendáis y veáis contemplando grandes misterios de nuestro Criador.

En otras ciencias comienzan por el entendimiento y acaban en él, esta mística teología y ciencia divinísima comienza de voluntad amando y particí- 
pase al entendimiento y al fin acábase en acto anagógico de inflamado amor. Aquí sabe más el idiota santo que el gran letrado porque hecha el alma una con Dios por amor es como el labrador que mirara al sol y osara negar que es de día, mas ni sabe dar cuenta que es el cuarto planeta el que ve, ni dará razón si se lo preguntan en qué cielo está el sol. Mas porque ésta es la señora que llama a todas sus criadas a su servicio, según dice Salomón (Prov 31,15), y las sabe a la luz de la razón y altura de la contemplación.

$Y$ porque es el fin para que fuimos criados unirnos por amor al criador, ejercicio más del cielo que de los peregrinos que andamos en la tierra, será bien avisar aquí dos cosas: ha de tener un aviso grande el cristiano para gozar de este ejercicio angélico, y es que a los principios no desmaye aunque le parezca dificultoso ejercitarse en esta unión divinal porque ni el pintor luego en una o dos licciones es maestro ni el tañedor de arpa en un día queda diestro músico. Primero hace muchos dibujos y echa borrones el que quiere primeramente pintar, y el tañedor hace muchas disonancias antes que sepa menear los dedos por las cuerdas, mas al fin la costumbre y ejercicio vale mucho y hace que con descanso obremos lo que antes nos daba trabajo.

Bien ansí en este ejercicio tan alto cumple no cansar ni dejar de producir actos de amor aunque sea con sequedad y nos parezca que no vale todo nada. No esperemos tiempo sino ejercitémonos siempre, no miremos lugar, sino en todo lugar levantemos nuestra afición a Dios, teniendo entendido que cada acto, estando en gracia, aunque sea friamente, tiene delante de Dios nuevo merecimiento y le responde en el cielo nuevo grado de gloria. $Y$ aun mejor se alcanzan por esta vía las virtudes, y se vencen los vicios mejor que resistiéndoles con las virtudes contrarias. Claro parece esto en aquella sentencia de nuestro Salvador, el cual dijo de la Magdalena: sonle perdonados muchos pecados porque amó mucho (Luc 7,47). Luego por todo es el camino más cierto y más breve el amor de Dios.

Lo segundo hase de tener aviso, y ya mucho en esto y que siempre tengamos fin a tender a esta vía unitiva para gloria de Dios. San Pablo da este aviso y dice: todas las cosas haced a gloria de Dios, ansí el comer y el beber como todo otro ejercicio (I Cor 10,31; Col 3,17). Quiero decir que ni nos mueva el gran gusto que allí Dios nos da a nuestra alma cuando actualmente le amamos, ni tampoco el mérito que ganamos en obra tan alta, sino hacer la voluntad de Dios en todo y que sea Él glorificado, porque de otra arte no sería negarnos a nosotros mismos sino buscar nuestro interés, el cual aunque sea bueno, el más perfecto es buscar la gloria de Dios y su voluntad en todo. 


\title{
CAPÍTULO 11
}

\author{
DE LA VÍA UNITIVA
}

Leva eius sub capite meo et dextera illius amplexabitur me: la mano izquierda de mi esposo Cristo tengo debajo de mi cabeza y su brazo derecho me abraza (Cant 2,6).

La esposa en los cantares muy ejercitada en las dos vías pasadas, purgativa e iluminativa, nos declara aquí en palabras breves qué cosa es vía unitiva.

Esta unión de amor es un reposo que el alma halla en su centro que es Dios, un olvido de todo lo criado, y aun el alma se olvida de sí misma. Es un recibirla Cristo en sus brazos después que llega cansada de rodear plazas y barrios como la esposa lo hizo buscando a su esposo (Cant 3,2). Y finalmente es un favor que Dios hace a Moisés poniéndole en medio de una niebla oscura por seis días y llamándole a voces y dándole una luz admirable en la cual le habla y declara su voluntad (Ex 24,18). Es una noche buena que dijo David que era su alumbramiento en los regalos que sentía con Dios (Ps 138,11).

San Dionisio ${ }^{9}$ llama ciencia divinísima esta unión porque allí nada obra el entendimiento, solamente la voluntad se ejercita amando a Dios. Por tanto escribiendo a Timoteo dice: Oh hermano Timoteo, para recibir esta ciencia divinísima y para ejercitar los actos anagógicos, deja los sentidos y las intelecciones, levántate cerrados los ojos a recibir aquella unión del que es sobre todas las cosas y sobre todo conocimiento, porque ansí, libre de todo, serás ligeramente llevado a lo alto para sentir el rayo de las divinas tinieblas, $\mathrm{y}$ avísote que ninguno de los sabios sepa esta doctrina.

Aquí llama este santo doctor divina sabiduría la mística visión y gusto de Dios. Da la manera para las inflamaciones y elevamientos anagógicos que han de ser con actos de la voluntad cesando el entendimiento, y finalmente avisa que no se comunique esta delicada ciencia a los sabios presuntuosos sino a los humildes. Llamó rayo de tinieblas divinas esta elevación porque del gran resplandor que resalta en el ánima de aquella luz eterna a que está unida, queda nuestro entendimiento admirado y sola una cosa sabe decir y es aquello del rey David: cuán grande es, Dios mío, la multitud de vuestra dulzura la cual así diste a los que os temen (Ps 30,20).

De aquí sale el alma tan ciega para ver las riquezas y honras del mundo que las tiene por cruz muy pesada y las estima a peso de polvo. Y de este

9. De divinis nominibus, 7 . 
gusto suave sale con tanto hastío de todo pasatiempo que todo le sabe a hiel en esta vida, y aun le parece que es cosa cuasi imposible que los hombres amen otra cosa sino a Dios, ni tomen gusto en otra cosa que en Dios.

Y porque el alma en los brazos del esposo ansí recreada, tiene grandes prendas y promesas de él que le gozará en la gloria, osa decir no sólo que descansa en su brazo izquierdo sino que con su brazo derecho la rodea y recrea en la bienaventuranza a donde la unión será del todo perfecta.

Aquí entenderá cada cristiano cuán bien empleados son sus trabajos sirviendo como Jacob siete años en penitencia para venir a gozar de la graciosa Raquel (Gén 29,18), que es esta unión de amor de la cual aun aquí en esta vida gozamos.

\section{CAPÍTULO 12}

\section{DEL EJERCICIO DE LA VÍA UNITIVA}

Vulnerata charitate ego: Llagada está mi alma de la saeta de la caridad (Cant 4,9).

La esposa que con tanto cuidado se ejercitaba en esta vía unitiva decláranos aquí este ejercicio que hemos de tener nosotros en esta obra divinal, que llegándose el alma a Dios y haciéndose una en espíritu con Él, luego la hiere y llaga de herida saludable dándole un deseo afervorado y una hambre maravillosa de más y más amor al que ansí con su amor la llagó.

Nuestro Padre decía en sus Confesiones; Oh Señor, que habéis herido mi corazón con la saeta de vuestro santo amor ${ }^{10}$, por tanto traiga yo como saetas atravesadas en mis entrañas vuestras divinas palabras de manera que en este desafío de guerra llena de mucha paz que el alma trae con Dios, él sale con la victoria y ella sale vencida y herida, mas como Dios mandó en su Ley que el que hiriese a otro pagase la cura, huelga mucho el esposo que hizo la llaga de sanar y curarla a su costa y con su diligencia, mas también quiere que le llame el alma y que dé voces y diga: Dios mío, médico mío, mirad por vuestra enferma y llagada a quien vuestro amor llagó, sanadla con vuestra presencia que no tiene otro remedio.

Y no sólo sale llagada el alma de herida saludable, mas porque el herido puede huir el amor divinal, átala y cautívala en esta unión santa para que ya sea su prisionera.

Voz es de nuestro Dios aquella del profeta: en los cordelillos de Adán los traeré a mí, y con cadenas de caridad los ataré con beneficios de la crea-

10. Cfr. Confesiones $9,2,3$. 
ción y conservación (Os 11,4), como con cuerdas delgadas nos atrae Dios para sí, mas en la pasión de su Hijo labró cadenas de amor más fuertes para nos cautivar su amor; por esto dijo él mismo hablando de su cruz: cuando fuere levantado de la tierra atraeré todas las cosas tras mí (Jo 12,32), y aun porque el cautivo puede limar las prisiones y huir, hace otro efecto la caridad en nuestra alma y es enfermarla y dar con ella en cama. Voces son desta enferma aquella: decid a mi amado esposo que estoy enferma de amor (Cant 2,5).

Oh bienaventurada el alma que ya del todo ha enfermado de tan santa y saludable enfermedad, tiene calentura de amor de Dios, da voces sin comer ni beber pidiendo la presencia de Cristo. Ésta tal aborrece el mundo, nada gusta ni descansa en las criaturas suspirando por su criador. A Él envía recaudos cada momento, orando y llamando a los ángeles que sean sus mensajeros y la visiten en su enfermedad. No cabe en la camilla estrecha deste cuerpo mortal, anda de una parte a otra congojada pareciéndole todo el mundo un nido de avión (sic) pequeño.

Finalmente este gran amor de Dios deja el ánima que se llega por unión afectiva, desmayada y sin fuerzas, que es más que ser llagada, cautiva y enferma. Desmayado ha mi espíritu en vuestra salvación, Dios mío, dijo David (Ps 119,81). Aquí cae la Reina Sabá sin espíritu admirada de la majestad y sabiduría del gran rey Salomón, y dice que la mitad de lo que ve y conoce por experiencia no le habían dicho (I Reg 10,1) antes. Aquí muere del todo el viejo hombre, desaparece nuestro propio espíritu y voluntad, y queda el alma todo deificada y medida y conformada a la voluntad de su Criador. Qué regalos recibe estando así desmayada y cuasi sin sentidos transportada y elevada en Dios, más vale suplicar a la divina bondad que nos lo dé a sentir que no hablar lo que no se puede decir. Baste que el rey Asuero viendo a Esther su esposa con este desmayo se levanta de su trono y esfuerza el ánima que de amor desmaya con palabras de gran suavidad como nos dice la historia de Esther la Escritura (Est 15,12). Vuestro hermano soy, dice Cristo, no temáis alma, llagado habéis mi corazón, hermana mía, esposa, con uno de vuestros ojos, (Cant 4,9), mirándome con el afectuoso deseo que me tenéis. Válame Dios, qué misterios tan altos; el que antes llagó al alma se queja que ha recibido llaga y no en la mano ni en el pie sino en el corazón, porque el amor caritativo que sale de nuestro corazón va sin rodeo a dar al corazón de Dios.

Luego en este ejercicio grande es la ganancia del alma pues se le rinde Dios y se le da en posesión el reino del cielo y el mismo Dios. 


\section{CAPÍTULO 13}

\section{DE LOS MUCHOS FRUTOS QUE NACEN DEL AMOR UNITIVO}

Mihi adherere. Deo bonum est, et ponere in eo spem meam: gran bien para mí llegarme a Dios y poner en Él mi esperanza (Ps 72,28).

Aquí el santo rey David nos declara ser cosa de gran fruto para nuestra alma seguir esta vía unitiva con afectos anagógicos y celestiales de amor. Entenderemos los tesoros que en el ejercicio del amor continuo del amor hay si miramos al Apóstol San Pablo que dice ser la caridad paciente y ser benigna y que todo lo cree y espera (I Cor 13,4), esto es decir que la caridad es la fuente de todas las virtudes de la cual manan como ríos que salen del mar. Es la que virtualmente las contiene todas en manera que no hay paciencia sin caridad, no hay abstinencia ni benignidad sin ella, ni otra virtud que estime Dios y pague dando la vida eterna en premio. De donde tenemos que el resistir a los vicios con las virtudes contrarias es como esperar el golpe sobre buen escudo, y aunque no se recibe herida siéntese el golpe de la espada, más resistir con actos de amor y deseos inflamados en Dios es herir el cuerpo al contrario enemigo, a donde el trabajo es menor y más segura la victoria.

¿Quieres, hermano, ser paciente, benigno y casto? Ama mucho a Dios, gózate de hablar con él, de levantar muchas veces tu corazón en Él. Ejercítate sin cesar en movimientos extáticos y espirituales, que en ellos serás purgado más brevemente de tus pecados. En tal fuego se ahogan los bríos de tu triste carne, y con el deleite espiritual del alma morirá todo mal deleite.

¿No sabes que el amor es más fuerte que la muerte? (Cant 8,6). El cual enseñoreado del alma mata los sentidos y el propio querer y vence animosamente al mundo y a Satanás y todas sus tentaciones.

Gran bien nos es llegarnos a Dios por unión amorosa, y tener deseos inflamados en Cristo, porque esta ciencia y sabiduría celestial es aquella de quien dijo Salomón: viniéronme todos los bienes con ella juntamente (Sap $7,11)$.

¿Quieres ser fuerte?- Ama. ¿Deseas ser justo?- Ama ¿quieres alcanzar prudencia y temperancia? -ama continuamente. Amando poseerás las virtudes en grado heroico, no se te dando más de ser honrado que vituperado, no sintiendo más pena de ser rico que pobre. Porque, en una palabra, lo desgustado del amor, dice nuestro Salvador, que están trabados los profetas $y_{2}$ la ley (Mt 22,40). Y San Pablo afirma que el que ama ha acertado con todo lo que Dios mandó (Rom 13,8). 
Y porque ésta es gracia y favor que se da del cielo conviene que se humille el alma y que ponga en Dios su esperanza, no en sus merecimientos, que esto sería perderlo todo por soberbia; ni tampoco confiando de su industria, que vale nada sin el favor de Dios.

San Dionisio dice que nos levantemos en este ejercicio santo y que seremos elevados, quiere decir, que de nuestra parte hagamos algo al principio respondiendo a los llamamientos de Dios, el cual arrebata el alma ya movida en amor. Ni obra el entendimiento ni tampoco amando porque no sabe de si allí es hábil, como San Pablo, para ver la esencia divina aunque de paso y como quien va de camino, porque aun mora en carne mortal. Mas, porque en este alto ejercicio el cuerpo se enflaquece y debilita mucho, será bien que éste se haga con discreción reposando el alma cuando siente cansancio en una de dos columnas o sillas: compasión de los trabajos y pasión de Cristo, y en la compasión de las aflicciones de los prójimos. Y tenga aviso que cuanto más crece el amor tanto menos sentirá las penas de la muerte del Señor, antes se goza de ver la gran caridad que tuvo en padecer por nosotros y en los grandes frutos de aquella pasión. Y al contrario, creciendo más la caridad sentirá más los trabajos de sus hermanos y rogará más a Dios por ellos porque aun están en peligro en esta vida.

Sea, pues, la resolución de todo este tratado que el pecador se ejercite en la vía purgativa primero haciendo penitencia de sus culpas doliéndose de ellas y confesándolas, ore, ayune y dé limosna para que Dios le purifique su alma; después pase a la vía iluminativa considerando a Dios en sus criaturas que son espejos donde resplandece el poder, bondad y saber de Dios, y en cuya hermosura se ha de considerar aquella hermosura infinita del que las crió. También contemple la pasión de nuestro Salvador y los beneficios recibidos universales y particulares, refiriéndolo todo al amor de Dios.

Finalmente, el alma purificada y hecha la conciencia un espejo limpio sin orín del pecado, al menos sin culpa mortal, para que mejor reciba los rayos de luz divinal y sea resplandeciente a un lúmine según leemos de Moisés (Ex 34,29 ), que le salían grandes resplandores de luz por el rostro cuando descendió del monte a donde conversaba con Dios; pase ya el ánima al ejercicio más excelente que es la vía unitiva la cual difiere de la iluminativa; sin medio alguno, vuela el alma para Dios: unas veces siendo de la gracia levantada y movida sin alguna operación que ella haga, otras no más de acordarse que hay paraíso y que hay Dios, luego de esta memoria con más ligereza que una saeta sale y salta una centella de fuego en el alma que la inflama y junta a Dios, diciendo con David: Oh Rey mío y Dios mío, oh mi gloria y mi alegría, mi tesoro y mi paz, Dios de corazón, vos sois mi heredad eterna (Ps 72,26). Ay de mí, que mi peregrinación se dilata, oh ¿cuándo verné y paresceré delan- 
te de mi Señor? (Ps 119,5). También dice con San Pablo el cual se ocupaba en esta vía unitiva: Deseo ser desatado y estar con mi Redentor Jesucristo. (Fil 1,23).Vivo yo, ya no yo sino vive en mí mi Redentor Jesucristo (Gal $2,20)$. Oh divinal amor, abrasa ya mi corazón. Estas y otras cosas semejantes habla el alma llena de aquella abundante suavidad que su esposo Cristo le comunica, unas veces lo dice todo con gemido que le sale de lo profundo del corazón el cual rompe los cielos y se presenta a Dios sin tercería alguna, otras veces vocal y mentalmente hace estas oraciones breves que llama San Agustín jaculatorias porque son arrojadas del alma con gran fuerza de amor como saetas o dardos, que la batalla de amor entre el alma y Dios son de grande valor y merecimiento y exceden a las oraciones largas, y por eso estas jaculatorias son de varones perfectos.

Muchas cosas hay en este arte subtil, hermano, que os enseñará el Señor por su misericordia cuando os llegáredes a la oración; basten las ya dichas que en el ejercicio puestas son harto más breves que escritas aquí, no ceséis de ir adelante con este ejercicio aunque os sintáis al principio pesado y frío, porque algún día diréis con el rey David: ya, Señor, rompisteis mi ataduras, $y$ yo os sacrificaré sacrificio de alabanza (Ps 115,16), ya me liberaste quitando de mí todo inconveniente, toda afección e inclinación mala, por tanto os daré mi corazón libre unido a Vos por amor y alabando vuestra majestad, vuestra liberalidad y bondad que ansí ha enriquecido mi alma con los tesoros de su caridad y amor. 